\title{
Fundamental Study on Rope Vibration Suppression by Intermediate Evacuation Floor Using Risk Information
}

\author{
Suzuko Tamashiro ${ }^{1}$, Satoshi Fujita ${ }^{2}$, Kazuhiro Tanaka ${ }^{3}$, \\ Tomohiro Shiki ${ }^{4}$ and Shigeki Okamura ${ }^{5}$ \\ ${ }^{1}$ Graduate School of Tokyo Denki Univ. Dept. of Mechanical Engineering 5 Senju-Asahi-cho, \\ Adachi-ku, Tokyo, 120-8551, Japan, 18kmk20@ms.dendai.ac.jp \\ ${ }^{2}$ Graduate School of Tokyo Denki Univ. Dept. of Mechanical Engineering 5 Senju-Asahi-cho, \\ Adachi-ku, Tokyo, 120-8551, Japan \\ 3,4Toshiba Elevator and Building Systems Corporation, 1 Toshiba-cho, Fuchu-shi, Tokyo/Japan \\ 5 Toyama Prefectural Univ. Dept. of Mechanical Systems Engineering 5180 Kurokawa, Imizu-shi, \\ Toyama, 939-0398, Japan
}

Keywords: Lift Rope, Lift Travel, Intermediate Evacuation Floor, Seismic Response Analysis, Risk Information

\begin{abstract}
Lifts are the essential means of vertical transportation. Recently, lifts installed in the high-rise buildings are long travel, thus the lift ropes are becoming longer. The natural period of the high-rise buildings is longer than that of the conventional buildings [1]. In addition to the lift rope becomes longer, the natural period of the lift ropes become longer. Accordingly, the natural period of the lift ropes gets closer to the natural period of the building. Consequently, the lift ropes might be entangled with the equipment of wall when the lift ropes vibrate due to an external force, such as a strong wind and earthquake. Furthermore, secondary accident such as containment of passengers and lift service stop may occur. In the Great East Japan Earthquake in 2011, 2015 cases of problem such as the catch and the damage of lift ropes have been reported [2]. Operation of lifts after earthquakes are required for the security of the refuge course. Accordingly, the analytical method for comparative evaluation is investigated in this study. Furthermore, a method to prevent a catch by vibration reduction of the lift ropes is investigated. In the previous research, it was confirmed that the division of the lift travel is effective for reducing the response of the rope. When the lift travel was equally divided, the displacement of the upper lift became larger than that of the other lift. Accordingly, the effectiveness of the division ratio of lift travel was examined in this report. We investigated the catching of the lift rope using the finite difference analysis and risk assessment. As the result, the displacement of the upper lift was decreased by the division ratio. The probability of catching rope of the upper lift is reduced. Furthermore, it was confirmed that the risk of the catching rope reduces in probabilistic risk assessment.
\end{abstract}

\section{INTRODUCTION}

Earthquakes occur frequently in Japan, which causes various damages to lifts. Accordingly, lifts require various seismic countermeasures including reinforcement of seismic structure as part of buildings. One of the countermeasures is a vibration problem of the lift ropes. In recent years, numbers of high-rise buildings are increasing in the urban areas with the development of building technology. Lifts installed in the buildings use the long objects such as main rope, compensating rope and cables. Due to the high-rise of the buildings, the natural period of these long objects is prolonged. Because the natural period of the high-rise building is long, the natural periods of these long object becomes longer. Thus, the natural periods of the building and the natural periods of these long object approach and resonate due to disturbances such as long-period ground motions and wind. The rope collides with the hoistway due to swaying. As the result, the lift ropes catch on the protrusions in the hoistway, causing damage to the rope and the confinement of passengers. In Japan, the evacuation staircase is said to be effective as an evacuation method when lifts stop. However, it is difficult to evacuate high-rise buildings with the evacuation staircase. Moreover, there are many people in 
high-rise buildings. If those people evacuate all at once, they are likely to cause confusion and congestion. In recent years, evacuation places that people can temporarily evacuate on the middle floors of high-rise buildings during disasters such as earthquakes and fires are set up. In China, an "intermediate evacuation floor" that people can stay safely for a long-time during disasters, should be located. At that time, the evacuation methods using lifts are attracting attention. Accordingly, lifts that can be operated at the time of disaster are required.

Therefore, the lifts that can be operated even after earthquakes are investigated in this study. In the previous study, it was confirmed that the division of the lift travel is effective for reducing the response of the rope. When the lift travel was equally divided, the displacement of the upper lift became larger than that of the other lift. Accordingly, the effectiveness of the division ratio of lift travel was examined in this report.

\section{ANALYTICAL MODEL}

Construction of analytical method of traction type lifts is often used for high-rise buildings. Fig. 1 shows the dividing model and analytical model. Model A is case that lift with the long travel is installed alone. Model B is a case that the lift travel is divided into two sections (a model with two lifts installed). In this paper, we examined three patterns for model B, which the division ratios of 1:1, 1:2, and 1:3. In the analysis, the main rope is measured along the rope length from the top end. On the other hand, the compensation rope is measured along the rope from the bottom end.

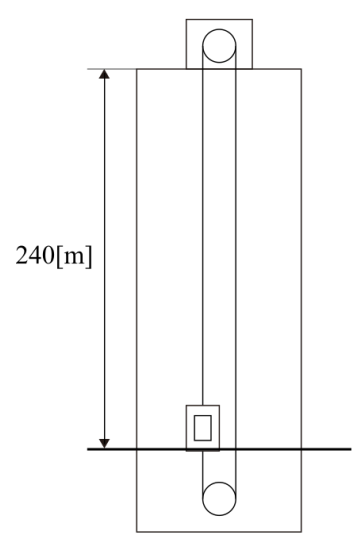

(a) Model A

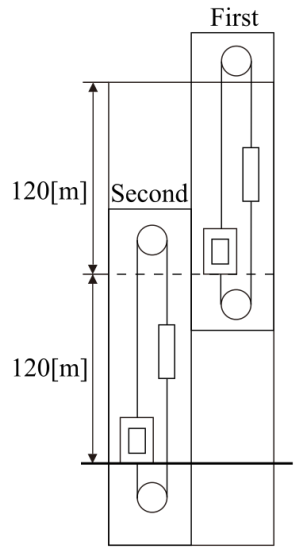

Division ratio $1: 1$

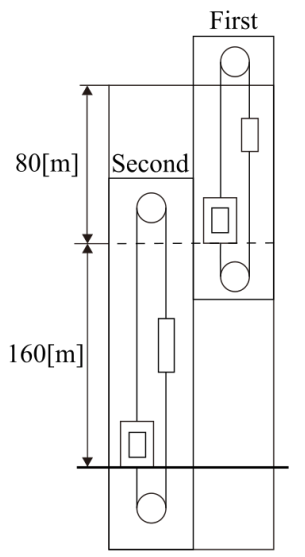

Division ratio 1:2

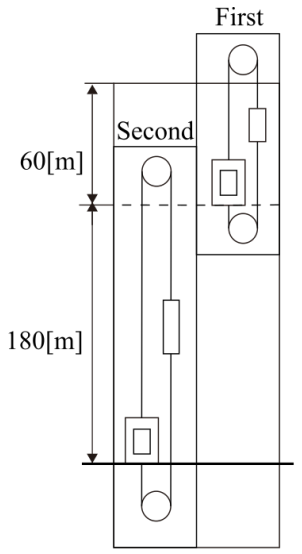

Division ratio 1:3

(b) Model B

Figure 1 The dividing model and analytical model

\subsection{Lift Rope Model}

The equation of motion of lift ropes as strings is shown in Eq. (1).

$$
\rho A \frac{\partial^{2} u}{\partial t^{2}}+C \frac{\partial u}{\partial t}-\frac{\partial}{\partial z}\left(T(z) \frac{\partial u}{\partial z}\right)=0
$$

Where, $\rho A$ is linear density of rope, $C$ is damping coefficient of rope, $T(z)$ is the tension considering the weight of the rope. $u$ is the horizontal displacement of the rope, $t$ is the time, $z$ is position of elements except traction machine side. Eq. (1) is valid when the lift is stationary. Eq. 1 is transformed to Eq. 2 by the difference approximation method. [3,4]. 


$$
\left(1+\frac{C \Delta t}{2 \rho A}\right) u_{j+1}^{i}=2\left(1-\frac{\Delta t^{2}}{\Delta z^{2}} \frac{T(z)}{\rho A}\right) u_{j}^{i}+\frac{\Delta t^{2}}{\Delta z^{2}}\left(\frac{T(z)}{\rho A}-g \frac{\Delta z}{2}\right) u_{j}^{i+1}+\frac{\Delta t^{2}}{\Delta z^{2}}\left(\frac{T(z)}{\rho A}+g \frac{\Delta z}{2}\right) u_{j}^{i-1}+\left(-1+\frac{C \Delta t}{2 \rho A}\right) u_{j-1}^{i}
$$

where $\Delta t$ is the time step, $\Delta z$ is length step, $i$ is the index corresponding to the space coordinates, $j$ is the index corresponding to the time coordinates, $g$ is gravitational acceleration. Fig. 2 shows a lattice point of the finite difference method.

\subsection{Building Model}

Fig. 3 shows an analytical model of building. The building is modeled as single-mass system. The equation of motion of building is as shown in Eq. (3).

$$
m \ddot{x}+c \bar{x}+k x=-m \ddot{z}_{H}
$$

where $\boldsymbol{m}$ is mass of the building, $\boldsymbol{c}$ is damping coefficient of the building, $k$ is stiffness of the building, $\ddot{Z}_{H}$ is the acceleration of input wave.

The natural period of building is calculated using Eq. 4 [4].

$$
T_{H}=0.025 \times H
$$

where $T_{H}$ is natural period of building, $H$ is height of building. The vibration mode shape of the building is not straight but curved. Accordingly, the vibration behavior of the position of the building is calculated using a correction coefficient, which is corrected by the vibration mode. The correction equations used for the correction coefficients are shown in Eq. 5 and 6.

$$
\begin{aligned}
& w=\alpha_{1} \times h+\alpha_{2} \times h^{2}+\alpha_{3} \times h^{3} \\
& h=\frac{H_{p o s i t i o n}}{H_{\text {top }}}
\end{aligned}
$$

where, $\boldsymbol{w}$ is the vibration mode shape of building, $H_{\text {position }}$ is the position measured along the building height, $H_{\text {top }}$ is the height at the top of the building, $\alpha_{1}=1.138, \alpha_{2}=0.5743, \alpha_{3}=-0.7083$. The coefficients $\alpha_{i}$ were calculated by the Stodola method. The response at the top of the building is calculated from Eq. 3. The response at each building height is calculated by multiplying the response obtained from Eq. 3 by the correction coefficient of each building height obtained from Eq. 5 and 6 . The top and bottom of the rope vibrate synchronously with the building. Accordingly, the response obtained by the above method is input to the top and bottom of the rope. 


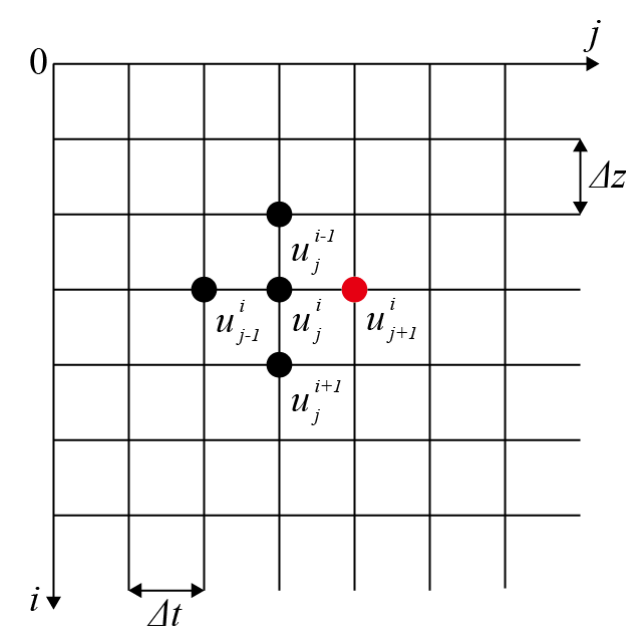

Figure 2 Lattice points
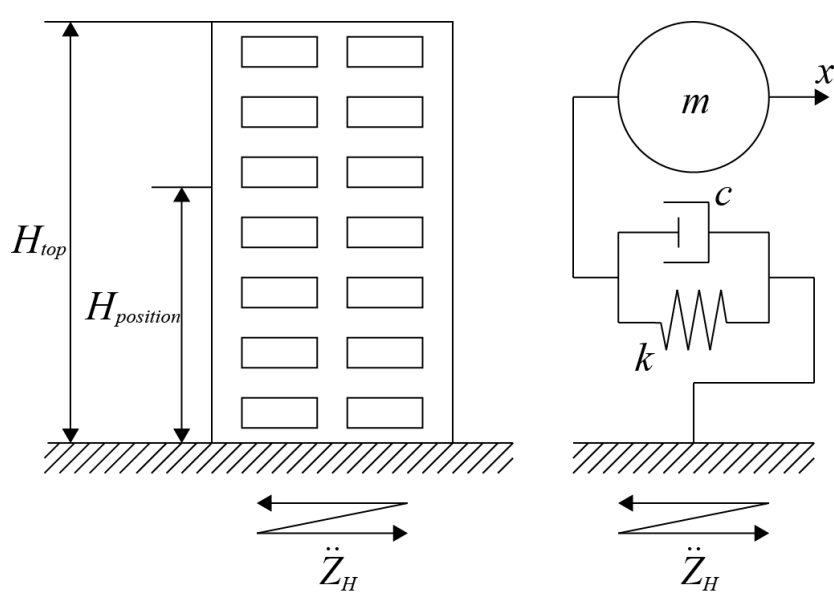

Figure 3 Structure model

\section{ANALYTICAL CONDITION}

\subsection{Specifications of Building and Lifts}

The seismic response analysis was conducted by the derived equations in Section 2. Table 1 shows parameters of building. Tables 2 to 3 show the parameters of each lift. Building height where the lift is installed is $240 \mathrm{~m}$. The rope length was determined taking into consideration the height of car and sheave, and the hoisting machine. The gap was determined in consideration of the actual lift dimensions.

Table 1 Specifications of building

\begin{tabular}{|c|c|}
\hline Building height [m] & 240 \\
\hline Natural period of buildings [s] & 6 \\
\hline Damping ratio of buildings & 0.02 \\
\hline
\end{tabular}

Table 2 Specifications of model A

\begin{tabular}{|c|c|c|}
\hline \multicolumn{2}{|r|}{ Roping } & $2: 1$ \\
\hline \multicolumn{2}{|r|}{ Cage mass $[\mathrm{kg}]$} & 2350 \\
\hline \multicolumn{2}{|c|}{ Counterweight mass [kg] } & 3450 \\
\hline \multicolumn{2}{|c|}{ Compensating sheave mass [kg] } & 554 \\
\hline \multicolumn{2}{|r|}{ Gap (cage side) [m] } & 0.8 \\
\hline \multicolumn{2}{|c|}{ Gap (counterweight side) [m] } & 0.2 \\
\hline \multirow{5}{*}{ Main rope } & Number of rope & 6 \\
\hline & Linear density $[\mathrm{kg} / \mathrm{m}]$ & 0.494 \\
\hline & Length(Cage side) [m] & $3 \sim 238$ \\
\hline & Length(Counterweight side) $[\mathrm{m}]$ & $3 \sim 238$ \\
\hline & Damping ratio & 0.002 \\
\hline \multirow{5}{*}{$\begin{array}{c}\text { Compensating } \\
\text { rope }\end{array}$} & Number of rope & 6 \\
\hline & Linear density $[\mathrm{kg} / \mathrm{m}]$ & 0.704 \\
\hline & Length(Cage side) [m] & $3 \sim 236$ \\
\hline & Length(Counterweight side) [m] & $3 \sim 235$ \\
\hline & Damping ratio & 0.02 \\
\hline
\end{tabular}


Table 3 Specifications of model B

\begin{tabular}{|c|c|c|c|c|c|c|c|}
\hline \multirow{2}{*}{\multicolumn{2}{|c|}{$\frac{\text { Division ratio }}{\text { Lift number }}$}} & \multicolumn{2}{|c|}{$1: 1$} & \multicolumn{2}{|c|}{$1: 2$} & \multicolumn{2}{|c|}{$1: 3$} \\
\hline & & First & Second & First & Second & First & Second \\
\hline & Roping & $2: 1$ & $2: 1$ & $2: 1$ & $2: 1$ & $2: 1$ & $2: 1$ \\
\hline & Cage mass $[\mathrm{kg}]$ & 2220 & 2220 & 2220 & 2220 & 2220 & 2220 \\
\hline \multicolumn{2}{|c|}{ Counterweight mass [kg] } & 3170 & 3180 & 3090 & 3220 & 3090 & 3220 \\
\hline \multicolumn{2}{|c|}{ Compensating sheave mass [kg] } & 167 & 167 & 167 & 167 & 167 & 167 \\
\hline \multicolumn{2}{|r|}{ Gap (cage side) [m] } & 0.8 & 0.8 & 0.8 & 0.8 & 0.8 & 0.8 \\
\hline \multicolumn{2}{|c|}{ Gap (counterweight side) [m] } & 0.2 & 0.2 & 0.2 & 0.2 & 0.2 & 0.2 \\
\hline \multirow{5}{*}{ Main rope } & Number of rope & 5 & 5 & 4 & 5 & 4 & 5 \\
\hline & Linear density $[\mathrm{kg} / \mathrm{m}]$ & 0.494 & 0.494 & 0.494 & 0.494 & 0.494 & 0.494 \\
\hline & Length(Cage side) $[\mathrm{m}]$ & $3 \sim 118$ & $3 \sim 124$ & $3 \sim 78$ & $3 \sim 164$ & $3 \sim 58$ & $3 \sim 184$ \\
\hline & Length(Counterweight side) [m] & $3 \sim 118$ & $3 \sim 124$ & $3 \sim 78$ & $3 \sim 164$ & $3 \sim 58$ & $3 \sim 184$ \\
\hline & Damping ratio & 0.002 & 0.002 & 0.002 & 0.002 & 0.002 & 0.002 \\
\hline \multirow{5}{*}{$\begin{array}{c}\text { Compensating } \\
\text { rope }\end{array}$} & Number of rope & 4 & 4 & 3 & 4 & 3 & 5 \\
\hline & Linear density $[\mathrm{kg} / \mathrm{m}]$ & 0.704 & 0.704 & 0.704 & 0.704 & 0.704 & 0.704 \\
\hline & Length(Cage side) $[\mathrm{m}]$ & $3 \sim 116$ & $3 \sim 121$ & $3 \sim 76$ & $3 \sim 161$ & $3 \sim 56$ & $3 \sim 181$ \\
\hline & Length(Counterweight side) [m] & $3 \sim 115$ & $3 \sim 121$ & $3 \sim 75$ & $3 \sim 162$ & $3 \sim 55$ & $3 \sim 182$ \\
\hline & Damping ratio & 0.02 & 0.02 & 0.02 & 0.02 & 0.02 & 0.02 \\
\hline
\end{tabular}

\subsection{Input Earthquake Wave and Specifications of Analysis}

Fig. 4 shows input earthquake wave, which was observed in 2011 off the Pacific coast of Tohoku Earthquake at Shinjuku North-South Direction [5]. Due to this earthquake a large number of damages of lifts were confirmed. Table 4 shows analysis time, time step and length step.

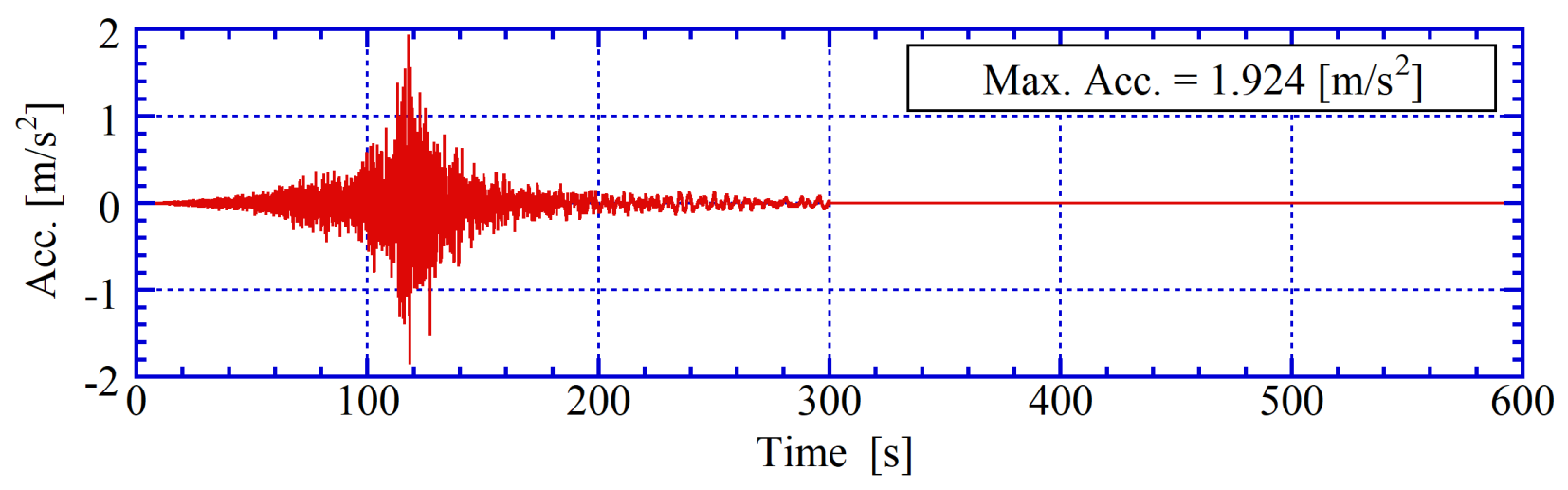

Figure 4 Input wave

Table 4 Specifications of Analysis

\begin{tabular}{|c|c|}
\hline Analysis time [s] & 600 \\
\hline Time step [s] & 0.005 \\
\hline Length step [m] & 1 \\
\hline
\end{tabular}




\section{PROBABILISTIC RISK ASSESSMENT}

Probabilistic risk assessment is a method to quantitatively evaluate the frequency of occurrence and the effect of the occurrence of an accident that may occur. In this report, we evaluate the risk of the rope catch. The evaluation formula for the fragility curve is as shown in Eq. 7 [6]. In this report, it is assumed that the probability distribution of various elements of the fragility curve is lognormal distribution as the method to make the fragility curve simple. Assuming that the probability distribution of various elements of the fragility curve is log-normal, Eq. 7 can be applied to various phenomenon.

$$
P_{f}\left(Z_{m}(s)\right)=\phi\left[\frac{\left(Z_{m}(s) / A_{m}\right)+\beta_{u} \phi^{-1}(Q)}{\beta_{r}}\right]
$$

where $P_{f}$ is the failure probability, $Z_{m}(s)$ is the velocity of the earthquake, $A_{m}$ is the median of the index due to catch of the rope, $\beta_{u}$ is a logarithmic standard deviation representing epistemic uncertainty, $\beta_{r}$ is the logarithmic standard deviation representing accidental uncertainty, $\phi(\cdot)$ is standard normal distribution, $\phi^{-1}(\cdot)$ is the inverse function of $\phi(\cdot), Q$ is the non-exceeding probability of failure probability considering epistemic uncertainty. When making a fragility curve based on Eq. 7, it is necessary to experimentally determine the median and the uncertainty of the index caused by the catching rope. In this report, as a basic examination of probabilistic risk assessment, if displacement occurs up to $0.8 \mathrm{~m}$ in car side and up to $0.2 \mathrm{~m}$ in counterweight side, the rope will not be caught at $99 \%$ probability. Uncertainty such as error in rope analysis, error due to principle of occurrence of the catch, and effects of dividing lift stroke are assumed to be constants. In this report, $\beta r$ and $\beta u$ are evaluated as 0.1 . Moreover, in this report, we evaluate by $95 \%$ reliability curve which is high reliability.

\section{RESULTS AND CONSIDERATION}

\subsection{Rope Analysis}

Fig. 5-8 show seismic response analysis results of the lift ropes. Fig. 5 shows the maximum displacement of each rope length of the main rope and the compensation rope in the model A. Fig. 6-8 show the maximum displacement of each rope length of the main rope and the compensation rope of the model B.

From Fig. 5, the maximum displacement of main rope increases in proportion to the length of the rope. The natural period becomes longer as the rope becomes longer. As the result, the natural period of the main rope is close to the natural period of the building. Also, the maximum displacement of compensation rope is obtained when the rope length is around $100 \mathrm{~m}$. After that, the displacement is decreasing, and the displacement increases in the vicinity of $240 \mathrm{~m}$. Because the compensation rope has lower tension than the main rope, the natural period of the compensation rope is longer than of the main rope. In the vicinity of $100 \mathrm{~m}$, it is considered that the first natural period of the compensation rope is close to the natural period of the building.

From Fig. 6, the displacement of the upper lift in both the main rope and the compensation rope is larger than the displacement of the lower lift. The displacement of the rope is considered to depend on the amount of vibration at the top and the bottom of the rope. Since the vibration input of the upper lift is larger than that of the lower lift, the displacement of the upper lift is considered to be large.

From Fig. 7, when the division ratio changes from 1:1 to $1: 2$, the displacement of the upper lift decreased. The vibration input of the upper lift is larger than that of the lower lift. The displacement is decreased by changing the division ratio and shorten the lift stroke (travel). Also, when the division ratio changes from 1:1 to $1: 2$, the displacement of the lower lift increased. The vibration input to the 
lower lift is smaller than that of the upper lift. The displacement was increased by changing the division ratio and getting longer the lift stroke.

From Fig. 8, the displacement decreases in the upper lift and increases in the lower lift compared to the cases where the division ratios are $1: 1$ and $1: 2$. As in the case of a $1: 2$ ratio, this is considered to be caused by a change in the division ratio.

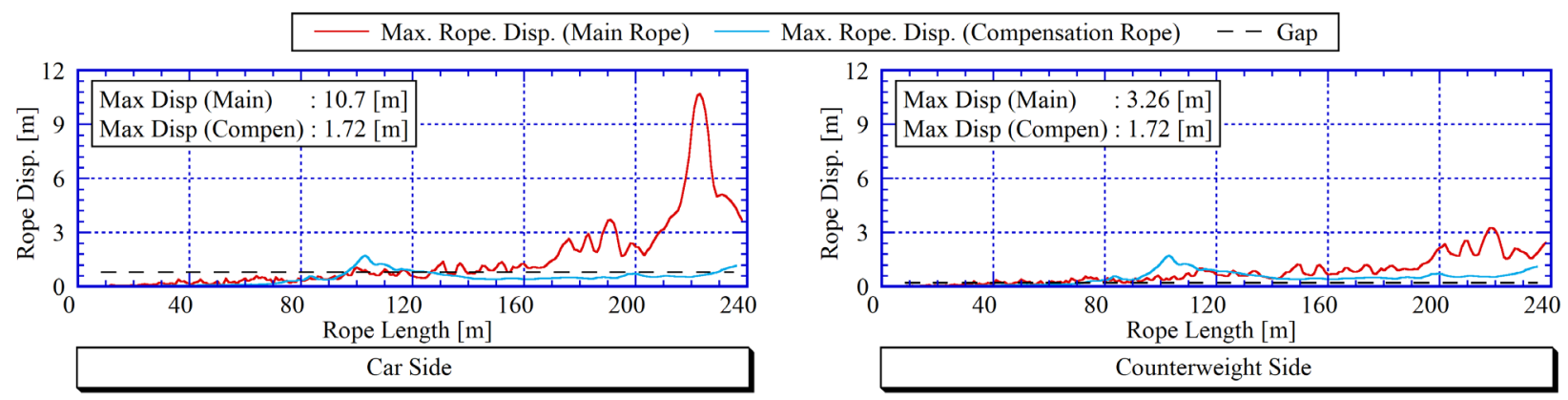

Figure 5 Numerical result of model A

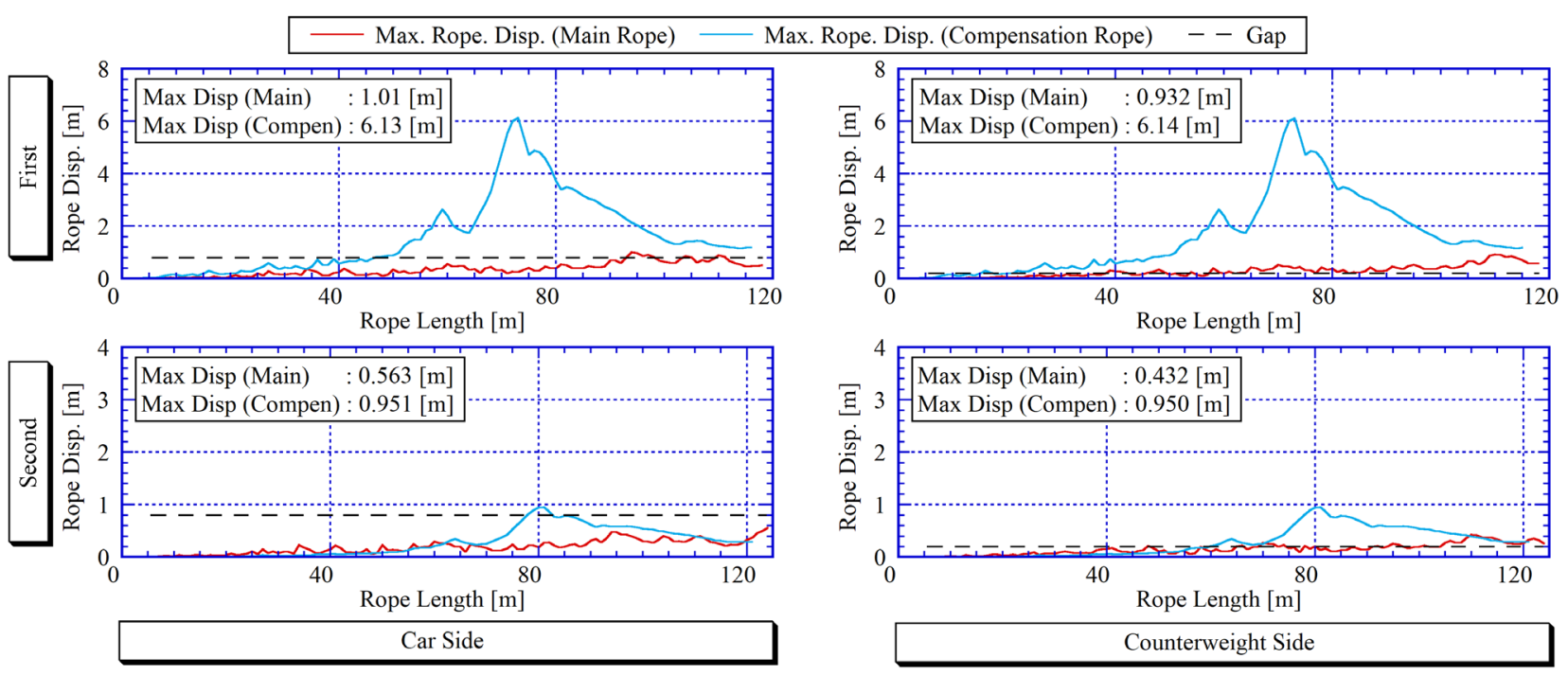

Figure 6 Numerical result of model B (1:1) 


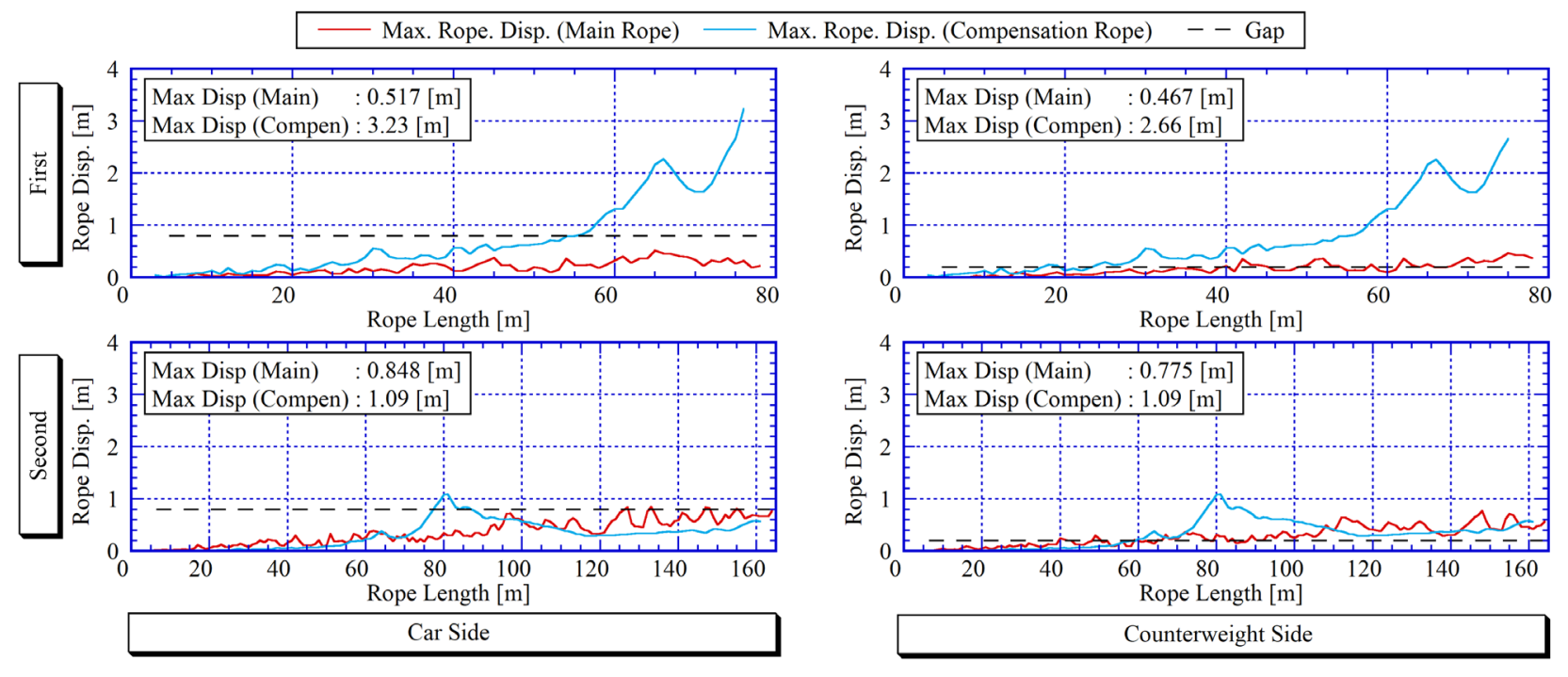

Figure 7 Numerical result of model B (1:2)

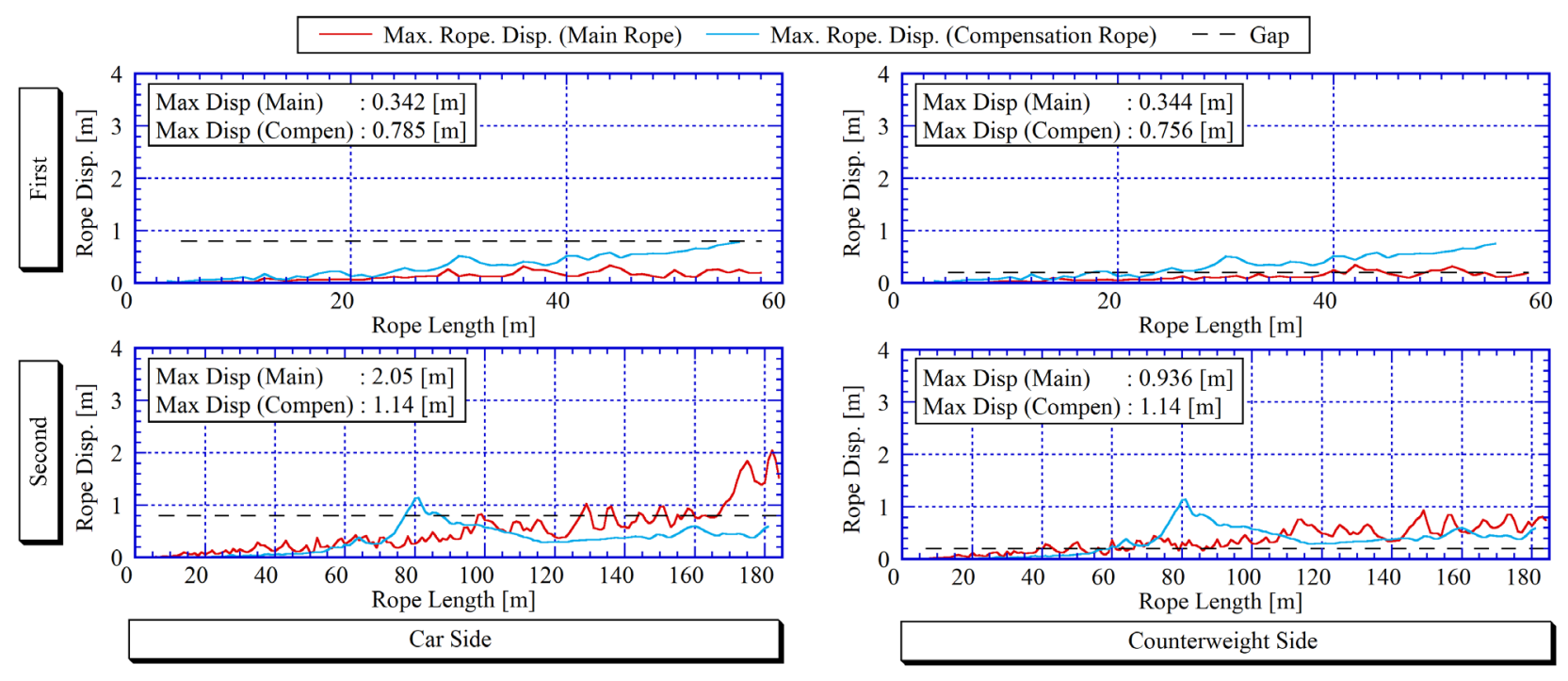

Figure 8 Numerical result of model B (1:3)

\subsection{Probabilistic Risk Assessment}

Fig. 9-12 show the fragility curves for each lift. Fig. 9-10 show the fragility curves for main rope and compensation rope of model A. Fig. 11-12 show the fragility curves for main rope and compensation rope of model B. The high confidence of low probability of failure (HCLPF) values for each lift are shown in Table 5. The HCLPF value, which guarantees the performance of the equipment mainly used in the nuclear field, is the value of 5\% failure probability in the $95 \%$ reliability curve.

From Fig. 9 -10 and Table 5, the main rope and the compensation rope in Model A have a high probability of catching rope even by small input seismic waves.

From Fig. $11-12$ and Table 5, the probability of the catching rope was lower in model B than in model A. Because by dividing lift stroke, the displacement of the lift rope decreased. When the division ratio is $1: 1$, the probability of the catching rope is larger in upper lift than in lower lift. Because upper lift vibrates more than lower lift, the displacement of upper lift becomes large. Division ratio changes from 1:1 to $1: 2$ or 1:3, and the lift stroke of upper lift shorten. Therefore, the 
probability of the catching rope also decreases. On the contrary, lower lift increases the probability of the catching rope because the lift stroke becomes longer.

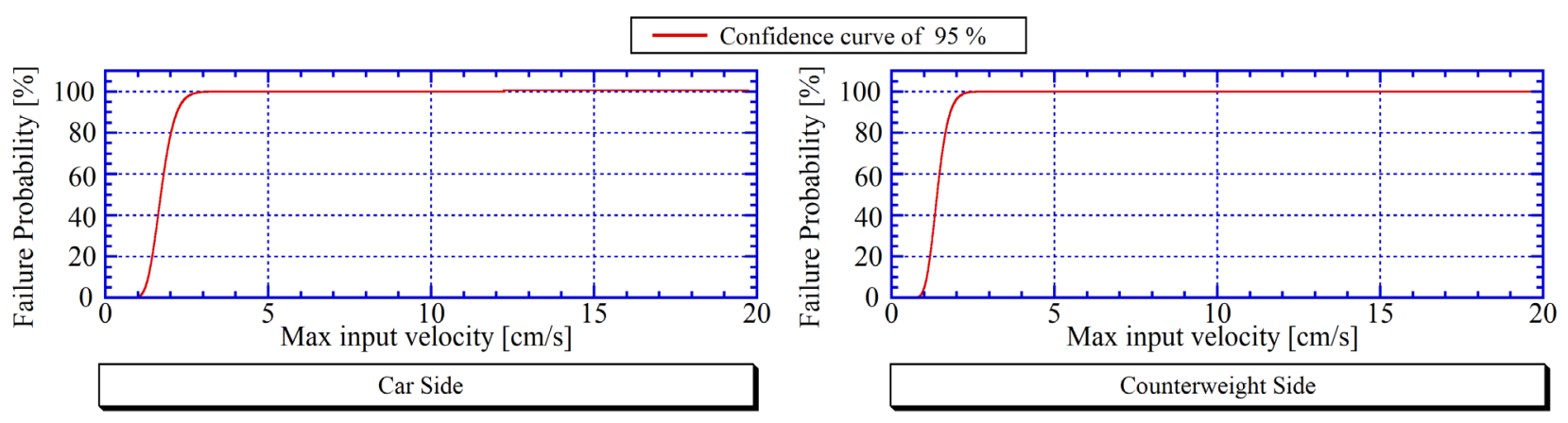

Figure 9 Fragility curve of model $A$ of main rope

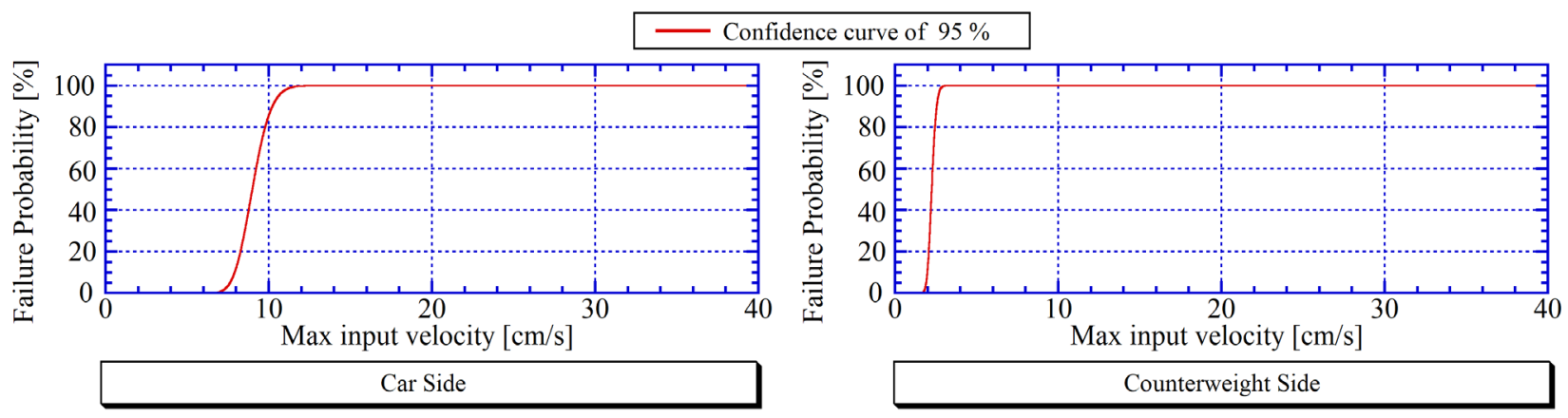

Figure 10 Fragility curve of model A of compensation rope

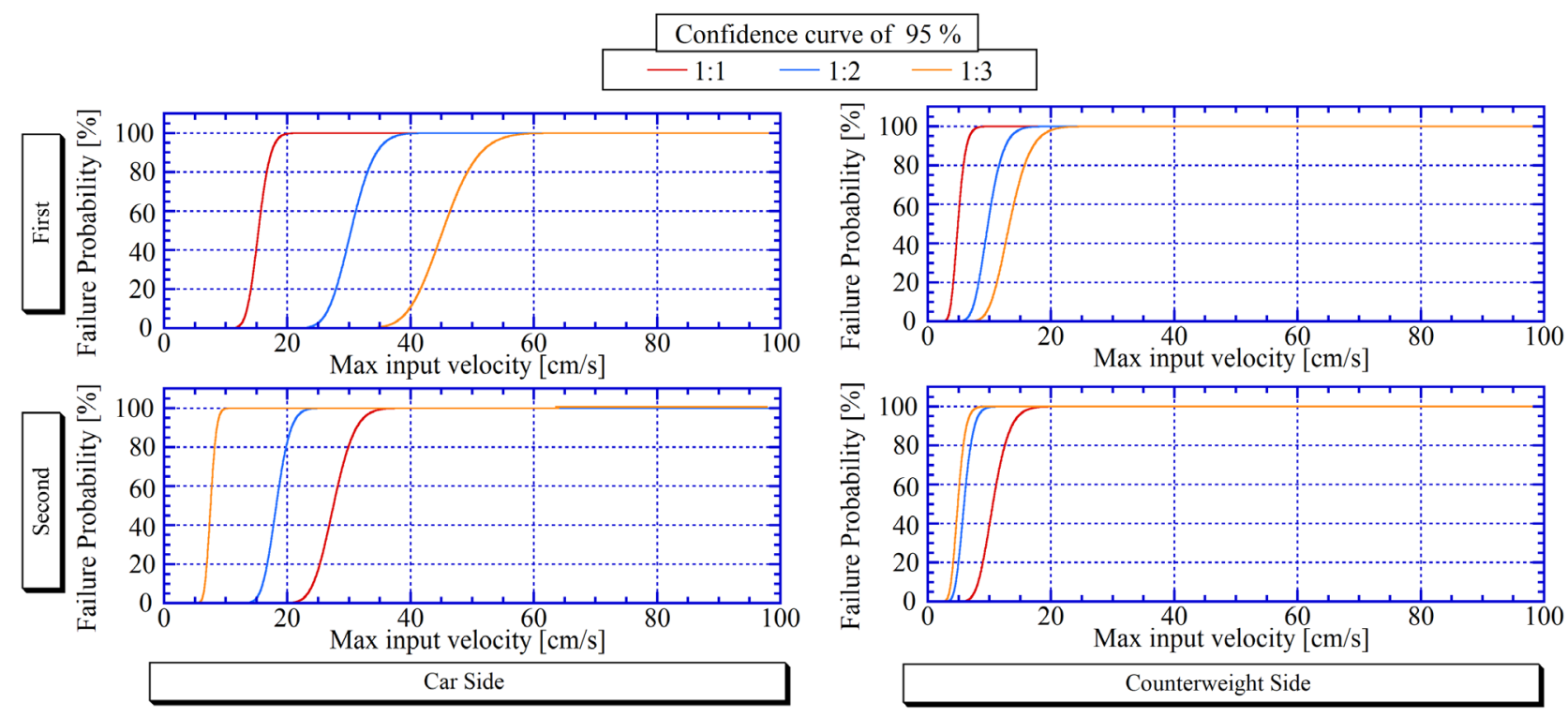

Figure 11 Fragility curve of model $B$ of main rope 


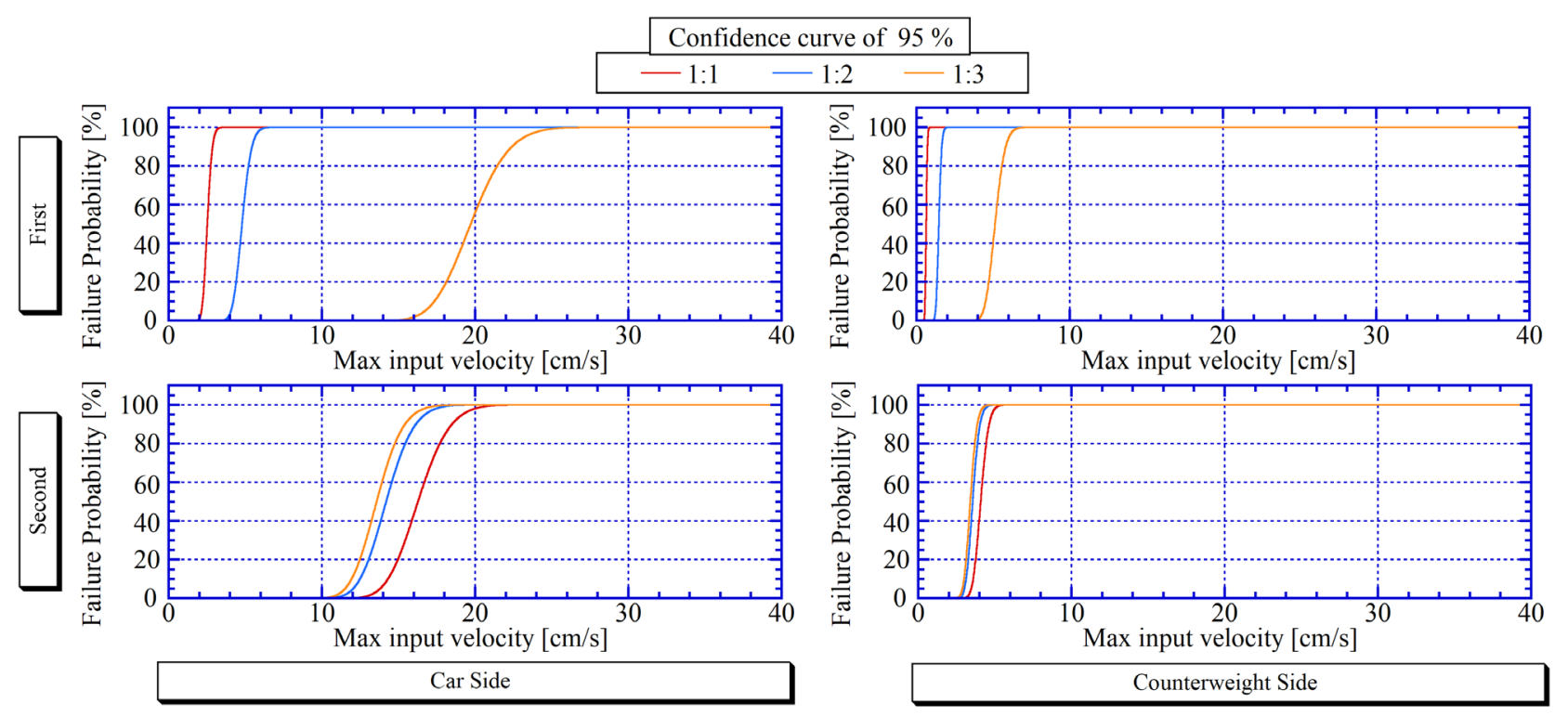

Figure 12 Fragility curve of model B of compensation rope

Table 5 HCLPF Value of each elevator

\begin{tabular}{|c|c|c|c|c|c|c|}
\hline & \multirow{3}{*}{ Division ratio } & \multirow{3}{*}{ Lift Number } & \multicolumn{4}{|c|}{ HCLPF $[\mathrm{cm} / \mathrm{s}]$} \\
\hline & & & \multicolumn{2}{|c|}{ Main Rope } & \multicolumn{2}{|c|}{ Compensation Rope } \\
\hline & & & Car side & Counterweight side & Car side & Counterweight side \\
\hline Model A & 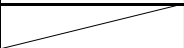 & 2 & 1.23 & 1.01 & 7.63 & 1.91 \\
\hline \multirow{6}{*}{ Model B } & \multirow{2}{*}{$1: 1$} & First & 13.0 & 3.52 & 2.14 & 0.536 \\
\hline & & Second & 23.3 & 7.59 & 13.8 & 3.45 \\
\hline & \multirow{2}{*}{$1: 2$} & First & 25.7 & 7.02 & 4.06 & 1.23 \\
\hline & & Second & 15.4 & 4.23 & 12.0 & 3.01 \\
\hline & \multirow{2}{*}{$1: 3$} & First & 38.4 & 9.53 & 16.7 & 4.34 \\
\hline & & Second & 6.40 & 3.50 & 11.5 & 2.88 \\
\hline
\end{tabular}

\section{CONCLUSIONS}

In this paper, as a vibration reduction method of lift rope in a high-rise building, the effectiveness of installing multiple lifts by dividing the lift travel and the effectiveness of changing the division ratio of the lifting travel were evaluated using the maximum displacement of rope and fragility curve. As the result, the occurrence probability of displacement and the probability of catching rope of the upper lift decreased, by changing the division ratio of the lift travel, and displacement and the probability of catching rope of the lower lift increased. By appropriately setting the division ratio in consideration of the vibration behavior and the length of the rope, the probability of the rope catch can be decreased. Therefore, the safety of the lift can be improved during and after seismic events including long period earthquake. 


\section{REFERENCES}

[1] Ishiyama Y., Seismic regulations and structural dynamics Basic knowledge for understanding the building structure, Sanwa Publishing Co., Ltd, 2008 (in Japanese).

[2] Miyata T., Fujita S., Shimoaki M., Damage to Elevators in the Great East Japan Earthquake, A collection of lectures at the 21 Traffic and Logistics Conference, 2012, pp.1-6. (in Japanese).

[3] Kimura H., Ito H., Nakagawa T., Vibration Analysis of Elevator Rope: Forced Vibration of Rope with Time - Varying Length, Transactions of The Japan Society of Mechanical Engineers, C71 (706), 2005, pp.1871-1876. (in Japanese). https://doi.org/10.1299/kikaic.71.1871

[4] Shibata A., Current Seismic Structural Analysis, Morikita Publishing Co., Ltd., 1981. (in Japanese)

[5] National Research Institute for Earth Science and Disaster Prevention, K-NET.KiK-NET, http://www.kyoshin.bosai.go.jp/kyoshin/, September 2016. (in Japanese)

[6] Nuclear Society Standard, Atomic Energy Society of Japan, Standards for Probabilistic Safety Evaluation due to Nuclear Power Plant Earthquakes, Atomic Energy Society of Japan, 2007, pp.313-315. (in Japanese)

\section{BIOGRAPHICAL DETAILS}

Suzuko Tamashiro is Master's student in Mechanical Engineering at Tokyo Denki University. She researches vibration suppression of lift rope.

Prof. Satoshi Fujita, a JSME (Japan Society of Mechanical Engineers) Fellow, has ten years of management experience as a director, a dean of school of engineering and currently a vice-president of Tokyo Denki University. He has been engaged in engineering research and development of seismic isolation systems and vibration control systems for buildings or key industrial facilities for over 35 years at both University of Tokyo and Tokyo Denki University.

Kazuhiro Tanaka, has been in Toshiba Elevator since 1995, is in charge of development for elevator system and representative of quality expert in development dept. He has developed many special elevators especially high-rise one like applied in tall tower. He is also chairperson of expert committee of machine technology in Japan Elevator Association since 2016.

Tomohiro Shiki entered Toshiba elevator in 2011. He belongs to the Development Dept. and is engaged in the development of cage mainly.

Associate Professor Shigeki Okamura has been in Toyama Prefectural University since 2018. Previously, he had been in the research institute and the manufacturer. He has been engaged in engineering research and development of seismic isolation systems and seismic evaluation method for the important facilities, such as, nuclear power plant/components. In addition, he had been engaged in seismic design of nuclear power plant/components. 